\title{
IL-17-deficient allogeneic bone marrow transplantation prevents the induction of collagen-induced arthritis in DBA/1J mice
}

\author{
Min-Jung Park, ${ }^{1,2}$, Hyun-Sil Park, \\ Hye-Joa Oh ${ }^{1,2}$, Jung-Yeon Lim ${ }^{1,2}$, \\ Bo-Young Yoon ${ }^{4}$, Ho-Youn Kim,', \\ Mi-La Cho ${ }^{1,2,5 *}$ and Seok-Goo Cho ${ }^{2,3,5 *}$ \\ ${ }^{1}$ Rheumatism Research Center \\ Catholic Research Institutes of Medical Science \\ ${ }^{2}$ Immune Tolerance Research Center \\ Convergent Research Consortium for Immunologic Disease (CRCID) \\ ${ }^{3}$ Catholic Blood and Marrow Transplantation Center \\ The Catholic University of Korea College of Medicine \\ Seoul 137-701, Korea \\ ${ }^{4}$ Department of Internal Medicine \\ Inje University Ilsan Paik Hospital \\ Seoul 411-706, Korea \\ ${ }^{5}$ Corresponding authors: Tel, 82-2-2258-7467; \\ Fax, 82-2-599-4287; E-mail, iammila@ catholic.ac.kr (M.L.C.) \\ Tel, 82-2-2258-6052; Fax, 82-2-599-3589; \\ E-mail, chosg@ catholic.ac.kr (S.G.C.) \\ *These authors contributed equally to this work. \\ http://dx.doi.org/10.3858/emm.2012.44.11.078
}

Accepted 28 August 2012

Available Online 21 September 2012

Abbreviations: BMT, bone marrow transplantation; CIA, collageninduced arthritis; Cll, type II collagen; Th17, IL-17-producing CD4 ${ }^{+}$ T cells; KO, knock-out; WT, wild-type; RA, rheumatoid arthritis; Treg, Regulatory $\mathrm{T}$ cell

\begin{abstract}
IL-17-producing $\mathrm{CD}^{+} \mathrm{T}$ cells (Th17) play important functions in autoimmune diseases and allograft rejection of solid organs. We examined the effects of IL 17 and its mechanism of action on arthritis in a murine collagen-induced arthritis (CIA) model using bone marrow transplantation (BMT) system. DBA/1J mice were administered a lethal radiation dose and then rescued with bone marrow derived from either wild-type (WT) or IL-17// mice on C57BL/6 background mice. CIA was induced after the bone marrow transplant, and dis-
\end{abstract}

ease progression was characterized. DBA/ $1 \mathrm{~J}$ mice with CIA that received IL-17'- donor bone marrow showed potently inhibited development and severity of clinical arthritis as compared with CIA mice that received WT bone marrow. Reduced secretion of the pro-inflammatory cytokines tumor necrosis factor- $\alpha$, IL-1 $\beta$, and IL-6, and collagen-specific T cell responses were observed in mice that received $\mathrm{IL}-17^{/-}$bone marrow. IL-17 blockade also inhibited effector T cell proliferation by reciprocally regulating the Treg/Th17 ratio. IL-17 blockade prevented joint destruction in mice with $\mathrm{ClA}$. These findings suggest that $\mathrm{CIA}$ with BMT is a viable method of immunological manipulation and that IL-17 deficiency suppresses severe joint destruction and inflammation in CIA mice. There may be clinical benefits in blocking IL-17 and BMT in the treatment of rheumatoid arthritis.

Keywords: arthritis, experimental; bone marrow transplantation; interleukin-17; Th17 cells; T-lymphocytes, regulatory; transplantation, homologous

\section{Introduction}

Th17 cells are a subset of T helper cells that play important roles in host defense and the pathogenesis of various human autoimmune and inflammatory diseases (Bettelli et al., 2007). Th17 cells produce interleukin (IL)-17A, IL-17F, IL-22, and IL-21, of which IL-17A and IL-17F mediate many of the downstream pathological effects in these cells (Iwakura et al., 2011). IL-17 acts in vitro and in vivo as a potent inflammatory cytokine. IL-17 has pleiotropic activities, one of which is to coordinate tissue inflammation by inducing tumor necrosis factor (TNF)- $\alpha, \quad \|-1 \beta, \quad$ IL-6, IL-8, granulocyte colony-stimulating factor (G-CSF), and monocyte chemoattractant protein-1 (MCP-1), in various types of cells, which mediate tissue infiltration and tissue destruction (Fossiez et al., 1998; Kolls and Linden, 2004). IL-17 also seems to play an important role in rheumatoid arthritis (RA) angiogenesis because of its ability to promote blood vessel growth (Pickens et 
al., 2010). Furthermore, IL-17 is involved in the host defense mechanism against lung bacterial infection, because of reduced recruitment of neutrophils to the lungs in IL-17R ${ }^{-/-}$mice (Ye et al., 2001).

Elevated IL-17 levels are found in serum and tissues of patients with various autoimmune diseases, including RA (Shahrara et al., 2008), multiple sclerosis (Tzartos et al., 2008), and systemic lupus erythematosus (Wong et al., 2000). In a previous study, we showed that IL-17 protein and mRNA levels were high in the serum and synovial fluid of patients with RA, and that IL-17 was expressed in the synovium of patients with RA. In the absence of IL-17, mice are resistant to the development of collagen-induced arthritis (CIA) (Nakae et al., 2003a; Lubberts et al., 2004), autoimmune encephalomyelitis (Komiyama et al., 2006), autoimmune uveoretinitis (Zhang et al., 2009), and other autoimmune diseases (Kikly et al., 2006). In line with this observation, our group previously showed that IL-17 producing T cells are increased in RA patients and Th17 are key effector cell in driving autoimmunity (Kim et al., 2005; Cho et al., 2006a; Lee et al., 2009).

Although Th1 cells had long been considered to be essential for driving autoimmune pathology, interferon (IFN)- $\gamma$ does not appear to be a major driver of autoimmunity, as IFN- $\gamma^{-/-}$mice are still susceptible to disease (Ferber et al., 1996; Chu et al., 2003). Interestingly, mice deficient in ICOS ("inducible costimulator," a co-stimulatory molecule for $T$ cells activation), are completely resistant to $\mathrm{CIA}$ and show a large deficit in IL-17 levels, although they produce normal levels of TNF- $\alpha$ and IFN- $\gamma$ (Lubberts, 2008). IL-23-deficient mice have no IL-17-producing $\mathrm{CD}^{+} \mathrm{T}$ cells, but the normal IFN- $\gamma$-producing Th1 cells are completely protected against the development of CIA (Murphy et al., 2003). Additionally, IL-17 plays a key role in the induction of experimental arthritis, as shown in IL-1 receptor antagonist-deficient mice, which develop arthritis spontaneously due to excessive IL-1 signaling (Nakae et al., 2003b). Consistent with this, IL-17 deficient mice are also resistant to CIA. These results point to a significant role for IL-17 in the immunopathology of various autoimmune diseases in mice.

Administration of type II collagen (CII) and complete Freund's adjuvant (CFA) to DBA $1 \mathrm{~J}$ mice induces the development of inflammatory erosive arthritis. $\mathrm{CIA}$ mice expressing the $\mathrm{H}-2 \mathrm{q}$ major histocompatibility complex (MHC) allele develop inflammatory synovitis of the paws, with synoviocyte proliferation, pannus formation, bone erosion, and cartilage destruction, strikingly similar to RA in humans. IL-17 is a pivotal cytokine in RA and is related to the major pathogenic mechanism of developing CIA [11]. The
CIA mouse model is useful for studying proinflammatory cytokines, such as IL-17, IL-1 $1 \beta$, IL-6, and TNF- $\alpha$, in T cells autoreactive to CIl (Myers et al., 1997).

In the present study, we generated allogeneic bone marrow chimeras of IL-17 deficiency in a DBA/1J background. This model may be useful to demonstrate the role of IL-17 in the induction of CIA. The aim of this study was to reveal the impact of IL-17 and its mechanism of action in the CIA model. Our results demonstrated that a deficiency in IL-17 signaling prevented CIA development. Using this system, we found that IL-17 signaling within the hematopoietic compartment promoted disease progression by regulating autoreactive $T$ cell responses and proinflammatory cytokine levels. Moreover, IL-17 blockade not only increased functionally suppressive Tregs, which inhibit proliferation of pathogenic Th17 cells, but also inhibited bone destruction in the CIA murine model. We conclude that IL-17 is indispensable for CIA development and suggest the therapeutic potential of IL-17 blockade in human arthritis conditions.

\section{Results}

\section{Establishing a bone marrow (BM) transplant CIA model}

We examined the fractioned irradiation (600 cGy $\times$ $2=1200 \mathrm{cGy}, 6-\mathrm{h}$ interval) necessary to destroy BM in the animals. Irradiated DBA/1J recipient mice were injected with BM from C57BL/6 (WT) or IL-17 knock-out (KO) donors. As shown in Table 1, DBA/1 J recipient mice (WT or IL-17KO BM) exhibited complete and stable donor chimerism with the $\mathrm{H}-2 \mathrm{~Kb}$ major histocompatibility complex allele in peripheral blood, spleen, lymph nodes, and bone marrow 12 weeks after transplantation (Table 1). Reconstitution of donor-derived cells in peripheral blood, spleen, lymph node, and BM was observed at normal B6 levels. No difference in the lineage pattern of any cell was observed between the groups, indicating that the presence of a systemic inflammatory autoimmune disease does not hamper the induction of allogeneic donor chimerism (Table 2). By irradiating DBA mice and rescuing them with $\mathrm{IL} 17^{-1 /}$ bone marrow, we created chimeric mice in which the majority of hematopoietically derived cells could no longer produce $\mathrm{IL}-17$, whereas the control group (WT) produced IL-17 normally. No mice exhibited signs of clinical graft-versus-host disease (GVHD; data not shown). 
Table 1. Induction of complete donor chimerism

\begin{tabular}{lcccc}
\hline & \multicolumn{4}{c}{ mean donor cells \% } \\
\cline { 2 - 5 } & PB & SP & LN & BM \\
\hline B6 $\rightarrow$ BA1J & $99.9 \pm 0.1$ & $99.2 \pm 0.2$ & $99.5 \pm 0.3$ & $96.6 \pm 0.1$ \\
IL-17Ko $\rightarrow$ BA1J & $99.8 \pm 0.1$ & $99.2 \pm 0.1$ & $99.6 \pm 0.2$ & $96.0 \pm 0.1$ \\
\hline
\end{tabular}

Percentages of donor cells were analyzed using FACS in peripheral blood (PB), spleen (SP), lymph node (LN), and bone marrow (BM). Values are expressed as mean \pm SEM ( $n=8$ mice per group).

Table 2. Analysis of immune reconstitution after bone marrow transplant

\begin{tabular}{clrrrrr}
\hline & \multicolumn{5}{c}{ mean donor cells \% } \\
\cline { 3 - 7 } & \multicolumn{1}{c}{ CD3 } & \multicolumn{1}{c}{ CD4 } & \multicolumn{1}{c}{ CD8 } & \multicolumn{1}{c}{ B220 } & Gr-1+ \\
\hline \multirow{2}{*}{ PB } & B6 $\rightarrow$ BA1J & $33.7 \pm 4.3$ & $22.6 \pm 0.7$ & $11 \pm 3.1$ & $37.6 \pm 5.7$ & $5.1 \pm 0.5$ \\
& IL-17Ko $\rightarrow$ BA1J & $37.1 \pm 4.2$ & $25.1 \pm 2.1$ & $11.9 \pm 1.4$ & $31.4 \pm 2.3$ & $7.6 \pm 2.6$ \\
sp & B6 $\rightarrow$ BA1J & $27.3 \pm 4.6$ & $19.1 \pm 2.3$ & $8.9 \pm 2.1$ & $39.6 \pm 1.6$ & $6.6 \pm 0.3$ \\
& IL-17Ko $\rightarrow$ BA1J & $24.4 \pm 4.5$ & $16.8 \pm 2.3$ & $8.9 \pm 1.8$ & $42.1 \pm 5.0$ & $5.9 \pm 0.4$ \\
dLN & B6 $\rightarrow$ BA1J & $60.7 \pm 1.0$ & $34.6 \pm 0.8$ & $27.2 \pm 0.9$ & $16 \pm 0.3$ & $5 \pm 0.3$ \\
& IL-17Ko $\rightarrow$ BA1J & $54.4 \pm 0.9$ & $30.4 \pm 0.6$ & $22.1 \pm 1.6$ & $18.2 \pm 2.0$ & $4.9 \pm 0.3$ \\
BM & B6 $\rightarrow$ BA1J & $5 \pm 0.1$ & $4.3 \pm 0.5$ & $3.3 \pm 0.5$ & $11.1 \pm 0.9$ & $1.7 \pm 0.1$ \\
& IL-17Ko $\rightarrow$ BA1J & $5.7 \pm 0.2$ & $4.9 \pm 0.1$ & $3.4 \pm 0.3$ & $11.7 \pm 1.4$ & $1.7 \pm 0.1$ \\
\hline
\end{tabular}

Analyses of cell surface antigens on peripheral blood (PB), spleen cells (sp), draining lymph node cells (dLN) or Bone marrow cells (BM) in the B6 $\rightarrow$ DBA1J (20 weeks after BMT) or the IL-17Ko $\rightarrow$ DBA1J (20 weeks after BMT) mice were analyzed using an FACS. The results are expressed as the mean SD of 6 mice.

\section{Preventative effects of IL-17KO BM transplant (BMT) on CIA mice}

At 4 weeks after BMT, arthritis was induced by two injections of CII in CFA. Compared with WT-BMT CIA mice, IL-17 KO-BMT CIA mice showed a significantly reduced severity (Figure $1 \mathrm{~A}$, left) and incidence of clinical arthritis (Figure $1 \mathrm{~A}$, right), indicating a strong therapeutic effect. WT BMT-CIA mice demonstrated destruction of the articular cartilage, bone synovial hyperplasia, and infiltration by inflammatory cells (Figure $1 \mathrm{C}$ ). In contrast, IL-17 KO-BMT CIA mice demonstrated no swelling or destruction of the articular cartilage (Figure 1C). Serum samples were analyzed for anti-collagen specific antibodies and proinflammatory cytokine by ELISA. As shown in Figure 1C, the Cll specific lgG1, $\lg \mathrm{G} 2 \mathrm{a}$, and total $\lg \mathrm{G}$ antibody levels were significantly lower in IL-17KO-BMT CIA mice as compared with WT-BMT CIA mice (Figure 1B). The serum levels of IL- $6, \mathrm{IL}-1 \beta$, and TNF- $\alpha$ decreased in IL-17KO BMT mice as compared with WT-BMT CIA mice (Figure 1D). Additionally, in immunohistochemical stain of the joints, IL- 6 , IL-1 $\beta$, and TNF- $\alpha$ + cells was decreased in IL-17KO BMT mice (Figure 1E). These results suggest that IL-17 blockade regulated the systemic inflammatory and humoral immune responses to $\mathrm{Cll}$.

\section{Regulation of the Cll-specific response by IL-17KO-BMT in CIA mice}

We examined the T cell response following Cll-specific stimulation to determine whether the reduction in $\mathrm{CIA}$ in transplanted IL-17 KO-BMT CIA mice was simply due to a defective $\mathrm{T}$ cell response to CII. A significant decrease was observed in the $T$ cell proliferative response to $\mathrm{Cll}$, as indicated by decreased ${ }^{3} \mathrm{H}$ thymidine uptake in IL-17KO-BMT CIA mice as compared with WT-BMT mice (Figure $2 \mathrm{~A})$. These results indicate that $\mathrm{IL}-17$ blockade during CIA development effectively suppressed the systemic autoimmune response to CII. While Tregs are known to regulate the immune response, Th17 cells are associated with the development and progression of joint inflammation. Based on these data, we next investigated the change in the Treg/Th17 ratio linked to the Cll-specific immune response. We found that the Treg/Th17 ratio increased profoundly in IL-17KO BMT mice as compared with the WT BMT group (Figure 2B). Because the IL-17 level in IL-17KO-BMT CIA mice decreased, the Treg/Th17 ratio increased relatively as compared with WT-BMT CIA mice. These results show that the IL-17 blockade in T cells shifted the Treg/Th17 balance toward Tregs. 
A

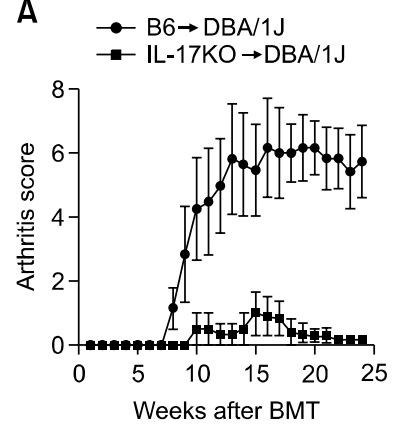

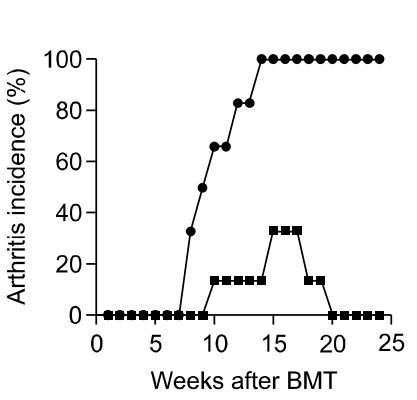

B

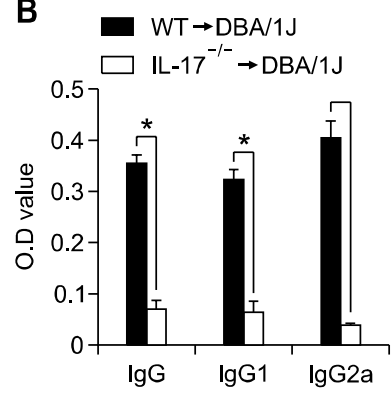

C
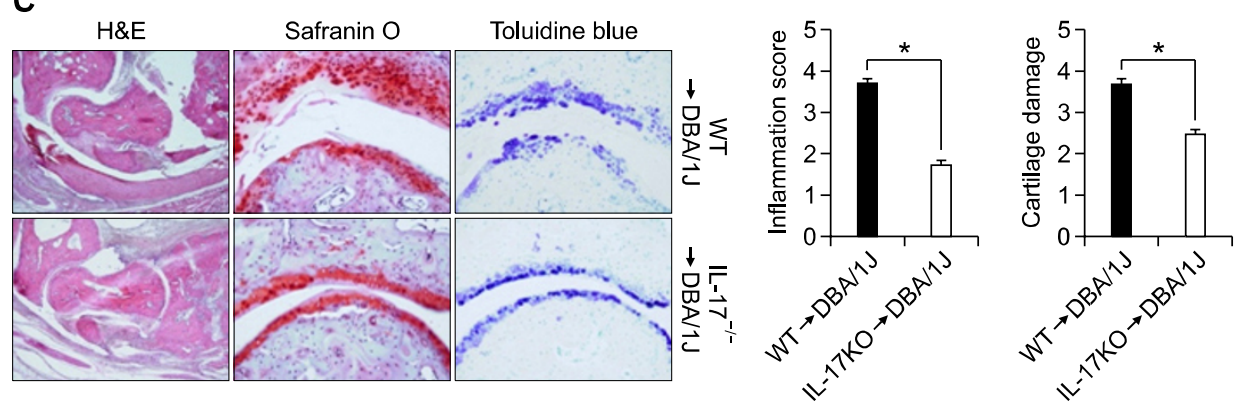

D

E
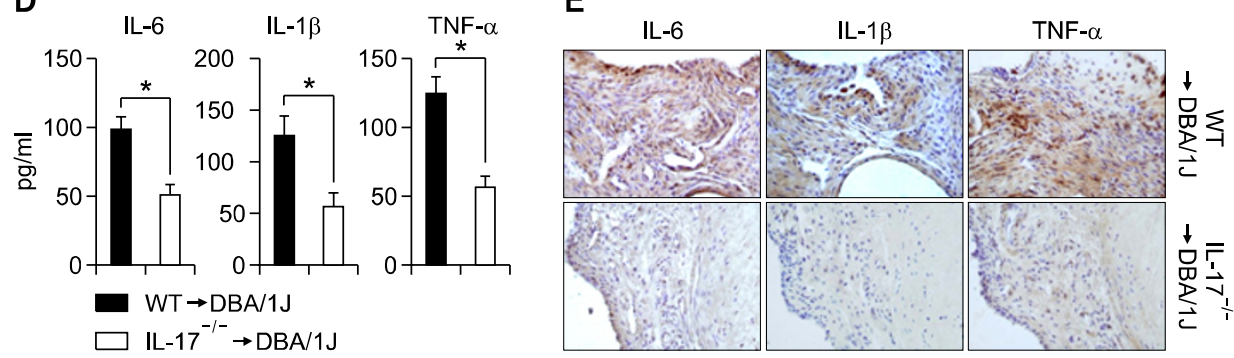

Figure 1. Reduced disease severity in IL-17 knockout $(K O) \rightarrow$ DBA chimeric mice. (A) Severity and incidence of arthritis in DBA/1J mice irradiated at 6 weeks and rescued with C57BL/6 $(\mathrm{B} 6 \rightarrow \mathrm{DBA})$ or interleukin $(\mathrm{IL})-17^{-/-}$bone marrow $\left(\mathrm{IL}-17^{-/} \rightarrow \mathrm{DBA}\right)$. After the bone marrow transplant, mice were rested for 4 weeks and then collagen-induced arthritis $(\mathrm{CIA})$ was initiated in transplant recipients $(n=10)$. Arthritis was monitored and scored as described in the Materials and Methods. Values are means \pm SEM. (B) Levels of IgG, IgG1, and IgG2a antibodies to type II collagen (aCII) in serum from each group of mice 10 weeks after the primary immunization, as measured by ELISA. Values are means \pm SEM of optical densities (OD). ${ }^{*} P<0.05$. (C) Representative joint sections from each group of mice 8 weeks after the primary immunization. Left, hematoxylin and eosin (H\&E) staining showing synovial inflammation. Original magnification, $\times 100$. Middle, safranin 0 staining showing cartilage erosion. Original magnification, $\times 200$. Right, toluidine blue staining. Original magnification, $\times 200$. Graphs show the mean \pm SEM inflammation and cartilage erosion scores for each group. ${ }^{*} P<0.05$. (D) Inflammatory cytokine expression in bone marrow transplant (BMT) chimeric mice. The levels of cytokine in serum from each group of mice 10 weeks after the primary immunization, as measured by ELISA. Values are means \pm SEM. ${ }^{*} P<0.05$. (E) Joints obtained from each group examined for the expression of IL-1 $\beta, I L 6$, and TNF- $\alpha$ by immunohistochemistry $(\times 200)$ or ELISA.

\section{Analysis of the $T$ helper cell population in IL-17KO-BMT in CIA mice}

To investigate the change in $T$ helper cells following IL-17 deficiency in CIA mice, we analyzed the levels of $\mathrm{T}$ helper (Th)-related cytokines and transcription factors in the $\mathrm{CD} 4^{+} \mathrm{T}$ cells of each group. The percentages of IL-10-producing $\mathrm{CD} 4^{+} \mathrm{T}$ cells and Tregs were higher in IL-17KO-BMT CIA mice as compared with WT-BMT CIA mice. However, the percentage of Th1 and Th2 cells was not significantly different between the groups (Figure 3A). Subsequently, we observed helper T cell cytokine patterns in the culture supernatants of each group. Following the anti-CD3 stimulus, the levels of IL-10 and TGF- $\beta$ were higher in $\mathrm{CD}^{+}{ }^{+} \mathrm{T}$ cells from IL-17KO-BMT CIA mice as compared with $\mathrm{CD} 4^{+} \mathrm{T}$ cells from WT-BMT CIA mice (Figure 3B). The production of IFN- $\gamma$ and IL-4 was not significantly different among the groups. These findings are consistent with those of the previous FACS analysis. A similar pattern of differential $T$ helper cell lineage-specific transcription factor expression was also observed in $\mathrm{CD} 4^{+} \mathrm{T}$ cells from IL-17KO-BMT CIA mice as compared with $\mathrm{CD} 4^{+} \mathrm{T}$ cells from WT-BMT CIA mice (Figure $3 \mathrm{C}$ ). It is well 
A

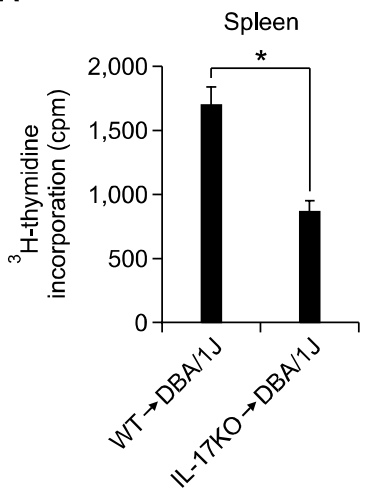

$\mathrm{dLN}$

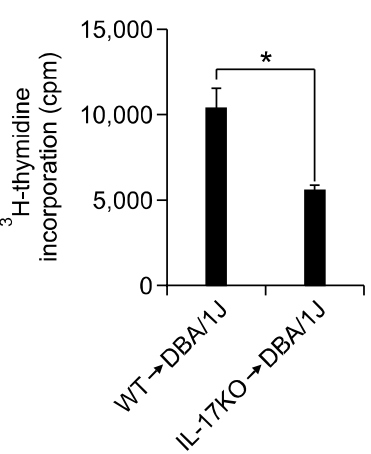

B

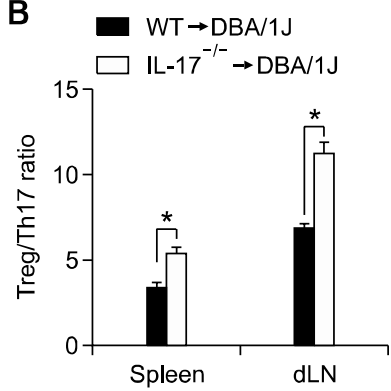

Figure 2. Type II collagen (CII) reactive T cell response in interleukin (IL)-17 knockout (KO)/DBA chimeric mice. (A) Proliferative response by spleen and

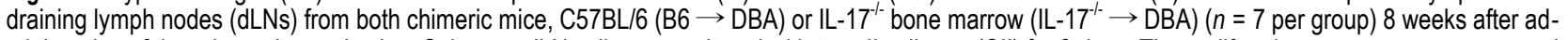
ministration of the primary immunization. Spleen or dLN cells were cultured with type II collagen (CII) for 3 days. The proliferation response was measured by incorporation of ${ }^{3} \mathrm{H}$-thymidine. Graph shows the mean \pm SEM. (B) Type II collagen (CII) specific Treg/Th17 regulation in spleen and draining lymph nodes (dLNs) from both chimeric mice. At 8 weeks after primary immunization, the spleens and dLN obtained from mice in each group were incubated with $40 \mathrm{~g} / \mathrm{ml}$ of type II collagen (CII) for 3 days. Cll-specific FoxP3:IL-17 ratio between CD4 ${ }^{+} T$ cells in the spleen and dLN. Bars show the mean \pm SEM. ${ }^{*} P<0.05$ by Student's t-test.

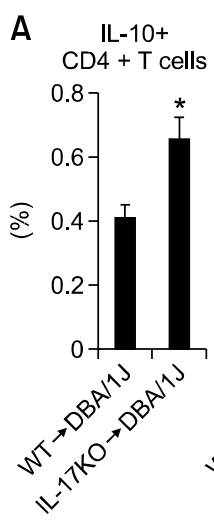

IFN-r+
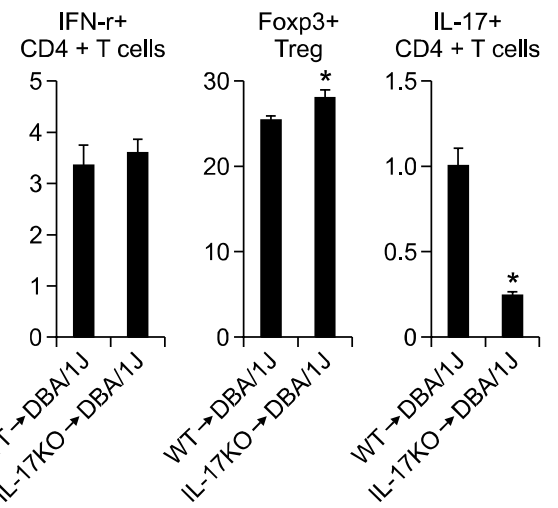

C

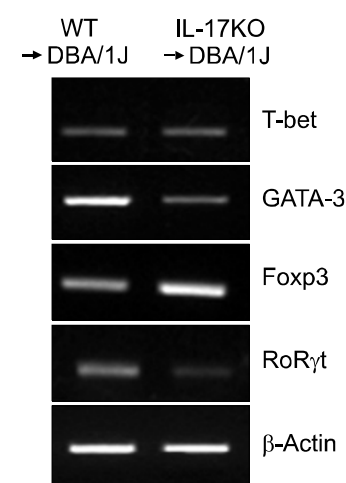

D
B
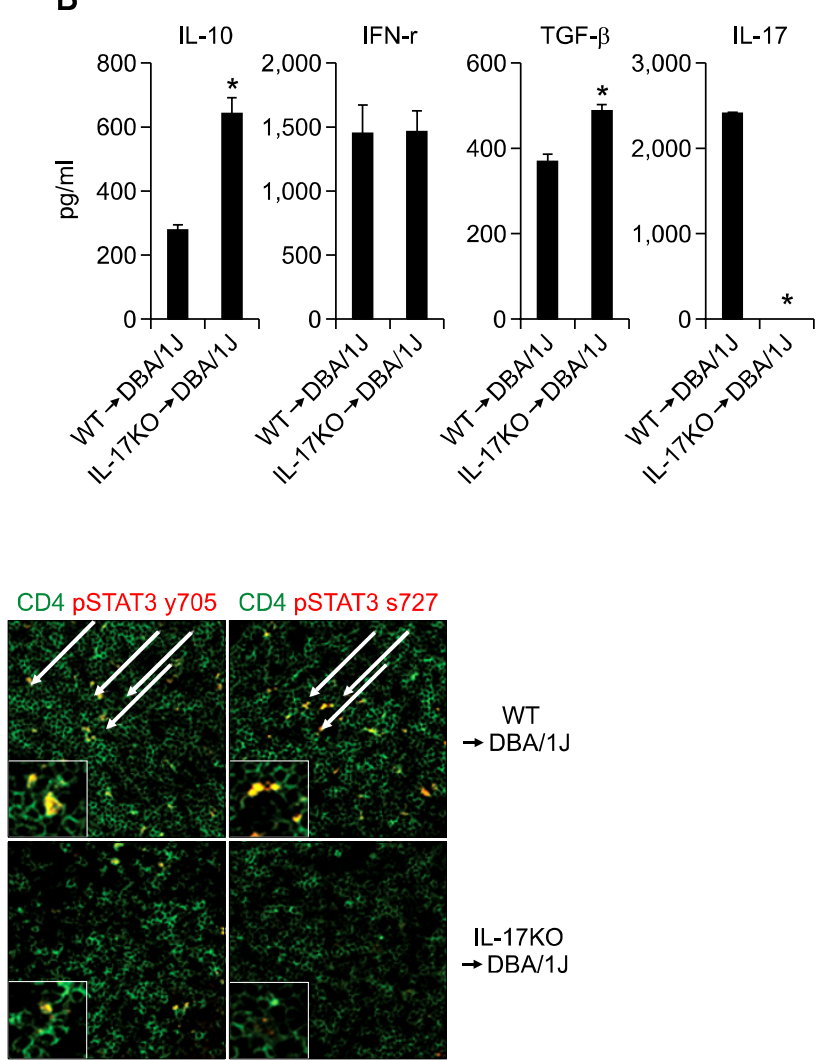

Figure 3. Analysis of Thelper cell population in interleukin (IL)-17 knockout (KO)/DBA chimeric mice. Cytokine production by $\mathrm{CD}^{+} \mathrm{T}$ cells from both chi-

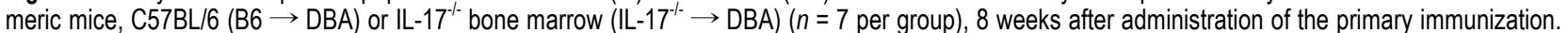
(A) Isolated $\mathrm{CD}^{+} \mathrm{T}$ cells were stimulated with anti-CD3 plus irradiated APC for $48 \mathrm{~h}$. The percentages of IL-10, IFN- $\gamma$, Foxp3, and IL-17 expression in $\mathrm{CD}^{+} \mathrm{T}$ cells were determined via intracellular labeling plus flow cytometric analysis. (B) Production of cytokines in the culture medium was measured by ELISA. Data are shown as means \pm SEM, $n=5-8$ mice/group ( ${ }^{*} P<0.05$ ). Bars indicate combined means \pm SD. ${ }^{*} P<0.05$. (C) mRNA expression level of T cell transcription factors, T-bet (Th1), GATA-3 (Th2), Foxp3 (Treg), and RORgt (Th17) cells in the CD4 ${ }^{+}$T cells from both chimeric mice were analyzed by RT-PCR. (D) Confocal analysis of phospho-STAT3 expression in T cells. CD4 and pSTAT3 cells were stained with antibodies specific for CD4 (green) and phospho-STAT3 Tyr705 or Ser727 (red). Merged green and red is shown as yellow (pSTAT3 expression in CD4 ${ }^{+}$T cells). Original magnification, $\times 400$ for panels D. All insets, x1000. 
A

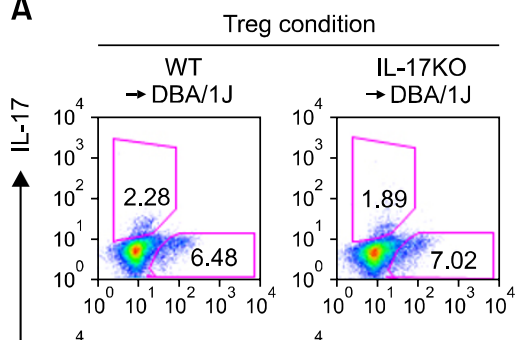

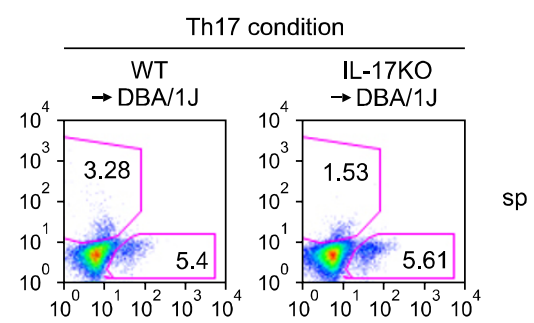
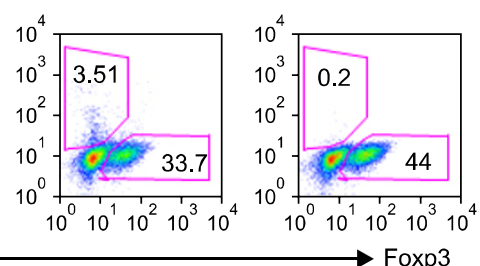

dLN
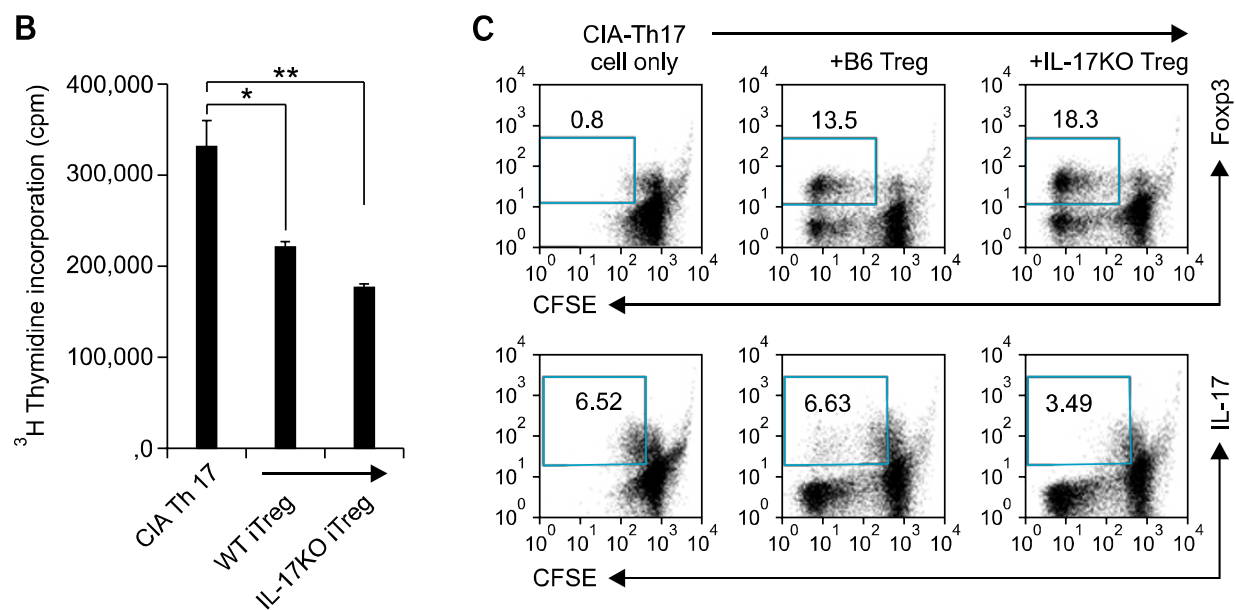

Figure 4. Inhibition of effector T cell proliferation/response by interleukin (IL)-17 knockout (KO) bone marrow transplant (BMT)-induced Tregs. (A) CD4 ${ }^{+} \mathrm{T}$

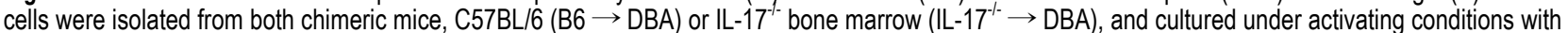
Treg or Th17 polarizing conditions for 3 days, respectively. [Treg condition (Left): anti-CD3 and anti CD28 in the presence of recombinant $h$ TGF- $\beta$, Th17 condition (Right): anti-CD28 in the presence of recombinant IL-6, TGF- $\beta$, anti-IL-4, and anti-IFN- $\gamma$ ]. Representative FACS plot depicting Foxp3 or IL-17 expression by $\mathrm{CD}^{+} \mathrm{T}$ cells. (B) $\mathrm{CD} 4^{+} \mathrm{CD} 25^{+} \mathrm{T}$ cells sorted from the above Treg condition cell cultures (a, left) were assessed for their suppressive capacity. $\mathrm{CD}^{+} \mathrm{CD} 25^{+} \mathrm{T}$ cells $\left(5 \times 10^{4}\right.$ cells) were cultured with irradiated $(5,000 \mathrm{rad})$ APCs $\left(5 \times 10^{4}\right.$ cells $)$ and Th17-conditioned culture T cells $\left(5 \times 10^{4}\right.$ cells $)$ isolated from CIA mice in the presence of Cll for $72 \mathrm{~h}$. The proliferation of effectors (Th17-conditioned T cells) was measured by incorporation of ${ }^{3} \mathrm{H}$-thymidine. Values are presented as means $\pm \mathrm{SEM}$. ${ }^{*} P<0.05$, ${ }^{* *} P<0.01$. Data shown are representative of three independent experiments. (C) The regulatory effect of Treg in each group of mice. Treg were generated in vitro, sorted to $>99 \%$ purity, and cultured with effector cells. Treg cells from each group were cultured with CFSE-labeled $\mathrm{CD}_{4}^{+}$effector T cells from CIA mice. After 3 days, proliferation of effector cells co-cultured with Treg from B6 or IL-17KO was measured by CFSE dilution. Percentages of dividing effector cells (determined by CFSE incorporation) are shown. Data shown are representative of three independent experiments.

known that STAT3, a signal transduction molecule of inflammatory cytokines, plays a key role as a positive regulator of RoRrt and IL-17 expression. Our results also show that $\mathrm{CD} 4^{+} \mathrm{T}$ cells in IL-17-deficient BMT-CIA mice exhibited decreased phosphorylated-STAT3, Y705, and Y727 expression (Figure 3D). These results indicate that decreased STAT3 activity suppressed proinflammatory cytokine production.

\section{Suppression of Cll-reactive effector T cell proliferation by iTregs from IL-17KO-BMT in CIA mice} We compared the ability to drive Treg differentiation in $\mathrm{CD}^{+}{ }^{+} \mathrm{T}$ cells isolated from WT BMT and IL-17 KO-BMT CIA mice in an in vitro Treg culture condition and then analyzed the suppressive capacity of the induced Tregs. As shown in Figure 4A, Foxp3 ${ }^{+}$Treg cells increased in the spleen $(7.2 \pm$ 0.3 versus $6.2 \pm 0.2, P>0.01)$ and draining lymph nodes $(75.8 \pm 1.6$ versus $70.4 \pm 1.7, P>0.05)$ of IL-17 KO-BMT CIA mice as compared with WT BMT mice. Moreover, Treg differentiation in $\mathrm{CD} 4^{+} \mathrm{T}$ cells isolated from dLN of IL-17 KO BMT-CIA mice 


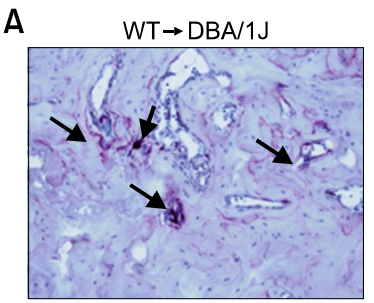

$\mathrm{IL}-17 \mathrm{KO} \rightarrow \mathrm{DBA} / 1 \mathrm{~J}$
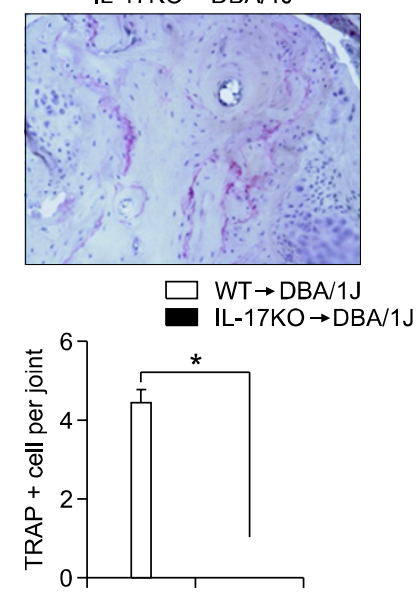
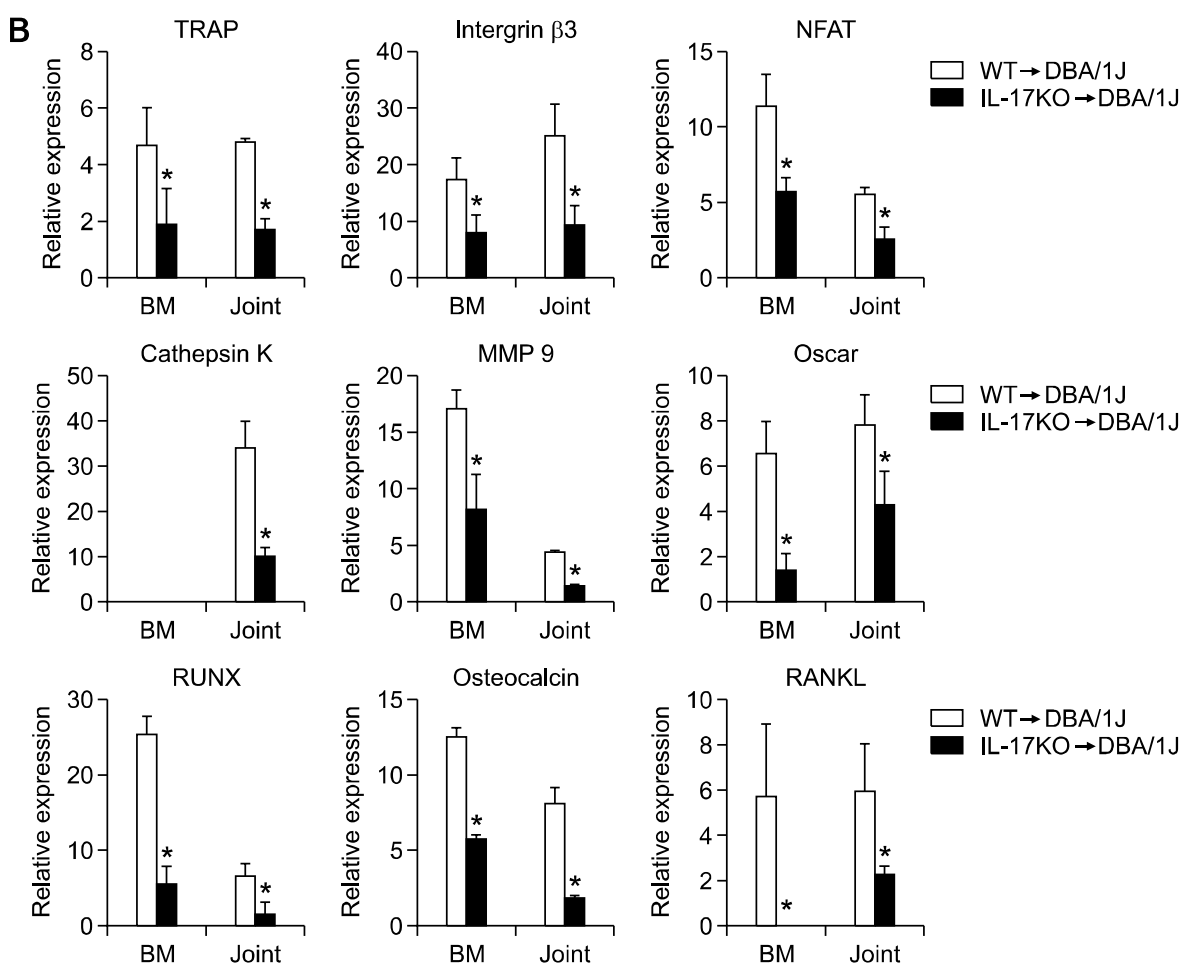

Figure 5. Inhibition of osteoclastogenesis in interleukin (IL)-17 knockout (KO)/DBA chimeric mice. (A) Tartrate-resistant acid phosphatase (TRAP) staining of paraffin sections from the joints of chimeric mice, C57BL/6 $(\mathrm{B} 6 \rightarrow \mathrm{DBA})$ or IL-17 ${ }^{-1-}$ bone marrow $\left(\mathrm{IL}-17^{-/} \rightarrow \mathrm{DBA}\right)$, showing multinucleated giant cells staining positive for TRAP. TRAP ${ }^{+}$osteoclasts are indicated by black arrows. Original magnification $\times 200$ in a. Bars show the mean \pm SEM results of three experiments, each of which was performed in triplicate. ${ }^{*} P<0.01$. (B) Real-time PCR analysis of osteoclast- and osteoblast-associated markers in joints and bone marrow. Relative gene expression was normalized against $\beta$-actin transcription levels. Each graph is representative of three independent experiments. ${ }^{*} P<0.01$.

cultured under Th17 polarizing conditions was more evident than that in WT-BMT mice $(42.93 \pm 1$ versus $32.9 \pm 1.8, P>0.002)$. We performed an in vitro Treg suppressive assay to further study expanded Treg-mediated effector $\mathrm{T}$ suppression. $\mathrm{CD}^{+} \mathrm{T}$ cells from CIA mice cultured under Th17 conditions were mixed with iTregs from WT-BMT or IL-17 KO-BMT CIA mice. As shown in Figure 4B, iTregs from IL-17 KO-BMT CIA mice exhibited a stronger capacity than iTregs from WT-BMT CIA mice. We also investigated the effects of Tregs from IL-17-deficient mice on Th17 cell differentiation. Adding iTreg from IL-17 KO BMT CIA mice to CFSE-labeled IL-17-producing cells resulted in an inhibition of the proliferation of effector $T$ cells producing IL-17( $3.4 \pm 0.1$ versus $6.4 \pm 0.1, P>$ 0.001 ), while favoring an increase in the frequency of Foxp ${ }^{+} \mathrm{T}$ cells $(18.4 \pm 0.5$ versus $0.96 \pm 0.1, P>$ 0.001 ) (Figure 4C). These results showed that activated Tregs in IL-17-deficient mice could affect differentiation of effector $T$ cells by regulating the Treg/Th17 balance.

\section{Inhibition of osteoclastogenesis differentiation in IL-17 KO DBA chimeric mice}

Decreased arthritis disease activity was associated with a reduction in bone erosion and synovial inflammation in joints. Our histology data showed IL-17 deficiency in CIA reduced bone erosion and cartilage destruction in the arthritic joints of the CIA mice. We investigated whether an in vivo IL-17 blockade would ameliorate joint erosion. TRAP staining was used to examine the potential inhibition of osteoclastic activity by IL-17 blockade during CIA development. As shown in Figures $5 \mathrm{~A}$ and $5 \mathrm{~B}$, most TRAP $^{+}$cells were observed at sites of bone erosion in WT-BMT CIA mice, whereas no staining was observed in CIA mice that received $\mathrm{IL}-17^{-1-}$ bone marrow.

We observed a significant decrease in mRNA expression of the osteoclast-related markers TRAP, RANK, NFATc1, MMP-9, integrin- $\beta 3$, cathepsin $\mathrm{K}$, and Oscar in BM and joint cells from IL-17 KO-BMT CIA mice as compared with WT-BMT CIA mice (Figure 5B). Interestingly, we also observed a lower level of the osteoblast-associated gene, RUNX, and osteocalcin expression increased more in BM and 
joint cells from IL-17 KO BMT-CIA mice, compared with that in BM and joint cells from WT-BMT CIA mice. These data suggest that IL-17 deficiency induced a decrease in osteoclast activity and gene expression involved in bone mass regulation.

\section{Discussion}

Our results showed that IL-17 contributed to the pathogenesis of inflammatory arthritis. DBA/1 J background mice, which were repopulated with transplanted BM from IL 17 deficient mice in our animal model, may be comparable with the population of cells arising from BM in patients with RA after IL-17 blockade therapy. CIA mice that received IL-17 ${ }^{-1-}$ BM had decreased autoreactive inflammatory cell recruitment proliferation, cytokine production, and reduced joint inflammation. Additionally, IL-17 $7^{-1-}$ DBA chimeric mice showed increased IL-10 and TGF- $\beta$ production by $\mathrm{CD} 4^{+}$T cells and functional Treg cells. Thus, IL-17 blockade may provide a potential target for the therapeutic treatment of autoimmune arthritis.

Several lines of evidence suggest that Th17 cells are important in the pathogenesis of experimentally induced autoimmune arthritis (Lubberts, 2010). IL-17 is expressed in the synovium of patients with RA (Chabaud et al., 1999) and in CIA mice (Lubberts et al., 2001). CIA severity is reduced in IL-17-deficient mice (Nakae et al., 2003a) and mice administered neutralizing IL-17 antibodies (Lubberts et al., 2004). We identified the function of IL-17 using allogeneic BMT.

Allogeneic BMT is a potentially curative therapy for various hematopoietic malignancies and immunological disease, such as idiopathic thrombocytopenic purpura in (NZW $\times$ BXSB) F1 mice, non-insulin-dependent diabetes mellitus in KK-Ay mice, and autoimmune diseases in MRL/MP-Ipr/lpr mice (Ikehara et al., 1985; van den Brink and Burakoff, 2002). Our group previously demonstrated that allogeneic mixed chimerism by BMT has the potential to correct established chronic inflammatory arthritis in the IL-1 $\mathrm{Ra}^{-1-}$ mouse model of RA (Cho et al., 2006b). A case of successful treatment of catastrophic antiphospholipid syndrome with autologous BMT has been reported. However, BMT has not been a safe option as compared with conventional immunosuppressive treatment to date. Several problems must be solved before allogeneic BMT becomes widely applied to autoimmune diseases. In addition to being a therapeutic method, BMT is a good method for identifying the function of specific genes in specific strains of mice without using $\mathrm{KO}$ mice. CIA mice are a rodent model of human RA. Mice with a H-2q (DBA/1J) background are highly susceptible to disease, whereas mice with a H-2b (C57BL/6) background are resistant to disease induction (Wooley et al., 1981). DBA/1 J mice are suitable for CIA pathogenesis research, such as measuring antigen-specific $T$ and B cell responses (Seki et al., 1988; Holmdahl et al., 1990). Thus, we transplanted BM from B6 background WT or IL-17 KO mice into DBA/1J mice. At 4 weeks after the BMT, DBA/1J mice transplanted with WT or IL-17 KO mice BM had CIA. Three weeks after the induction of CIA, WT-BMT mice developed arthritis with an earlier onset and a higher incidence than that in IL-17KO-BMT mice. We showed that mice lacking IL-17 BMT rarely developed arthritis and had almost normal joints without cartilage damage or inflammatory cell recruitment, indicating that IL-17 signaling is evidently involved in the induction of arthritis in CIA mice.

$\mathrm{T}$ cells are believed to play a critical role in orchestrating the inflammatory response in RA. Thus, suppression of antigen-specific T cell responses is of great importance in RA treatment. Our results show that this protective effect was associated with downregulation of the $\mathrm{Cll}$ reactive $\mathrm{T}$ cell response in the IL-17KO-BMT model. Direct evidence for this beneficial effect is that IL-17 blockade attenuated $\mathrm{CIA}$ systemic inflammation in the mice. IL-17 facilitates the production of many inflammatory cytokines and chemokines by activating immune cells (Hwang et al., 2004). Our results demonstrated that IL-17 deficiency blocks the production of proinflammatory cytokines, including IL-1 $1 \beta, \mathrm{IL}-6$, and TNF- $\alpha$, in vitro and in vivo. This may have affected the decreased PSTAT3 protein level. While IL-17 deficiency enhanced IL-10 production by $\mathrm{CD}^{+}{ }^{+} \mathrm{T}$ cells and Foxp3 ${ }^{+}$Tregs, it did not affect IFN- $\gamma$-producing $\mathrm{CD} 4^{+}$T cells. IL-10 is a signature cytokine for Tregs, and plays a key role in the control of self-antigen-reactive T cells in vivo (Groux et al., 1997). We demonstrated that IL-17 blockade inhibited the pathogenic immune reaction and upregulation of IL-10 was involved primarily in the induction of specific T cell tolerance.

Great interest has been focused on understanding the inverse relationship between Th17 cells and Tregs. A balance between Th17 and Tregs is crucial for immune homeostasis. TGF $\beta$ is required for Th17 and Treg differentiation and it can induce both Foxp3 and RORgt expression (Zhou et al., 2008). The balance of Th17 cells and Tregs is dependent on the cytokine environment, including IL-6, TGF- $\beta$, IL-21, IL-1, and IL-23 levels. One possible explanation suggests that Treg recruitment and proliferation may change the cytokine profile due to the IL-17 deficiency. Tregs play an important role in the prevention of autoimmunity, and they could modulate 
$\mathrm{ClA}$ severity (Bluestone, 2005). We observed that $\mathrm{CD}^{+}{ }^{+} \mathrm{T}$ cells from IL-17 KO-BMT mice show increased differentiation into functional Tregs, which suppressed proliferation of Cll-reactive $\mathrm{CD}^{+}{ }^{+} \mathrm{T}$ cells (effector) as compared with that in WT-BMT mice. In a co-culture experiment with effector cells, enhanced Tregs inhibited differentiation into IL-17 producing effector $T$ cells, but promoted differentiation into Foxp $3^{+} \mathrm{T}$ cells.

IL-17 acts directly on osteoclastogenesis by synergizing with RANKL signaling or driving gene upregulation in osteoblasts, which, in turn, drive osteoclastogenesis (Kotake et al., 1999; Sato et al., 2006). In the present study, we found that IL-17 deficiency inhibited bone destruction by preventing the formation of osteoclasts and downregulating the expression of osteoclast associated genes, such as TRAP, MMP9, integrin- $\beta 3$, NFATc1, and cathepsin $\mathrm{K}$. Additionally, we showed that IL-17 blockade induced downregulation of osteoblast-related genes (osteocalcin, Runx2, and RANKL) in the joints and $\mathrm{BM}$. We infer that IL-17 prompt the osteoblasts to osteoclasts differentiation signals, possibly through the induction of RANKL and regulation of gene expression of osteocalcin or Runx2, is an important of bone metastasis on osteoblastic cells. Thus, anti IL-17 therapy produced a powerful therapeutic effect in the treatment of joint destructive arthritis by regulating osteoclastogenesis-associated genes and RANKL expression.

Our results demonstrate that removing IL-17 signaling using a BMT system in a CIA model resulted in marked decreases in arthritis severity. Our observations bear a striking similarity to those reported by other investigators concerning an anti-joint inflammatory role of IL-17. Furthermore, we observed that IL-17 deficiency results in increased functionally suppressive Tregs and reduced levels of other Th17 lineage inflammatory cytokines. In summary, our results support the hypothesis that IL-17 plays a key role in the pathogenesis of inflammatory RA, supporting II-17 as a therapeutic target in RA.

\section{Methods}

\section{Animals}

Male DBA/1J (H2-kq), wild-type (WT), and $\mathrm{IL}-17^{-/-}$on a C57BL/6 (H2-Kb) background mice (Jackson Laboratories, Bar Harbor, ME) were maintained in a specific pathogen-free environment with standard laboratory mouse chow (Ralston Purina, St. Louis, MO). The animals were treated according to the regulations of the Catholic Ethics Committee of the Catholic University of Korea, in conformity with the National Institutes of Health guidelines.

\section{Bone marrow transplantation}

Recipient (DBA/1J) mice were exposed to a 1200-cGy dose of radiation from a Mevatron MXE-2 instrument (Siemens, New York, NY) with a focus-to-skin distance of $100 \mathrm{~cm}$ and a rate of $200 \mathrm{cGy} / \mathrm{min}$. In total, 1,200 cGy of radiation was administered in a split dose separated by 6 $\mathrm{h}$, and the mice were permitted to rest overnight. The next morning, the donor mice (WT or IL-17 ${ }^{-/ 2}$ on a C57BL/6 background mice) were sacrificed, and their femurs were removed. Bone marrow was harvested from femurs by flushing three times with phosphate-buffered saline (PBS) supplemented with $1 \%$ fetal calf serum (FCS) and filtering the fluid through a cell strainer. Cells were washed in PBS, counted with a hemocytometer, and resuspended at a concentration of $10^{7}$ cells $/ \mathrm{ml}$. Tail vein injections of $10^{6}$ donor cells $(100 \mu \mathrm{l})$ were then administered to each mouse in the recipient group, and the animals were rested for periods ranging from 5 to 12 weeks.

\section{Preparation of Cll}

Bovine Cll was kindly provided by Prof. Andrew Kang of the University of Tennessee. Cll was extracted in its native form from fetal calf articular cartilage and purified as described previously (Stuart et al., 1979).

\section{$\mathrm{CIA}$ induction and treatment}

CIA was induced after 4 weeks as described previously (Kim et al., 2002). Briefly, DBA/1J mice were injected in the base of the tail with $100 \mu \mathrm{g} \mathrm{Cll}$ emulsified in CFA. Two weeks later, $100 \mu \mathrm{g} \mathrm{Cll}$ with Freund's incomplete adjuvant was injected into a hind paw footpad as a booster injection. Clinical signs of arthritis were assessed visually in the wrist and ankle joints, as reported previously (Wooley et al., 1981).

\section{CIA histological evaluation}

A histological analysis was conducted to determine the extent of joint damage. Mouse joint tissues were fixed in $4 \%$ paraformaldehyde, decalcified in an EDTA bone decalcifier, and paraffin-embedded. The sections were then dewaxed using xylene and dehydrated through an alcohol series. Endogenous peroxidase activity was quenched with methanol $/ 3 \% \mathrm{H}_{2} \mathrm{O}_{2}$. Sections were routinely stained with hematoxylin and eosin, safranin-O fast green, and toluidine blue, and were evaluated blindly, as described previously (Camps et al., 2005).

Immunohistochemistry was performed using the Vectastain ABC kit (Vector Laboratories, Burlingame, CA). Tissues were incubated first with the primary anti-GFP antibody (Abcam Cambridge, MA) overnight at $4^{\circ} \mathrm{C}$, a biotinylated secondary linking $\mathrm{Ab}$, and finally a streptavidin-peroxidase complex for $1 \mathrm{~h}$ each. The final color product was developed using AEC chromogen (DAKO, Carpinteria, CA). Sections were counterstained with hematoxylin, and samples were photographed with an Olympus photomicroscope (Tokyo, Japan). 


\section{Cell culture}

All cell cultures were performed in RPMI 1640 (Invitrogen, Carlsbad, CA) supplemented with $10 \%$ FCS, 2 mM glutamine, $100 \mathrm{IU} / \mathrm{ml}$ penicillin, $0.1 \mathrm{mg} / \mathrm{ml}$ streptomycin, 0.25 $\mu \mathrm{g} / \mathrm{ml}$ amphotericin $\mathrm{B}$, and $2 \mu \mathrm{M} \beta$-mercaptoethanol. Spleen or draining lymph node (dLN) cells were cultured with $40 \mu \mathrm{g} / \mathrm{ml} \mathrm{Cll}$ to observe the $\mathrm{T}$ cell response to Cll. Treg cultures were supplemented with $5 \mathrm{ng} / \mathrm{ml}$ transforming growth factor (TGF)- $\beta$ (R\&D Systems, Minneapolis, MN) and Th17 conditions contained $10 \mathrm{ng} / \mathrm{ml} \mathrm{IL-6}$ (Invitrogen), 5 $\mathrm{ng} / \mathrm{ml}$ TGF- $\beta 1$ (R\&D Systems), $10 \mu \mathrm{g} / \mathrm{ml}$ anti-IL-4, and 10 $\mu \mathrm{g} / \mathrm{ml}$ anti IFN $\gamma$.

\section{Measurement of cytokines and Cll-specific IgG titers}

Concentrations of IL-10, IL-17, TNF- $\alpha$, IL-6, and IL-21 in cell culture supernatants and serum were measured using a sandwich enzyme-linked immunosorbent assay (ELISA; Duoset; R\&D Systems, Lille, France). Serum levels of antiCII IgG, IgG1, and IgG2a antibodies were measured using a commercially available ELISA kit (Bethyl Laboratories, Montgomery, TX).

\section{Proliferation assay}

Cells were pulsed with $1 \mu \mathrm{Ci}{ }^{3} \mathrm{H}$-thymidine (GE Healthcare, Piscataway, NJ) per well for the final $8 \mathrm{~h}$ of the $72-\mathrm{h}$ culture period. Finally, ${ }^{3} \mathrm{H}$-thymidine incorporation was determined using a liquid scintillation counter (Beckman. Fullerton, $\mathrm{CA})$.

\section{Flow cytometric analysis}

Mononuclear cells were immunostained with various combinations of the following fluorescence-conjugated antibodies: CD25, CD4, CCR7, Foxp3, IL-17, cytotoxic T lymphocyte antigen-4 (CTLA-4), and glucocorticoid-induced tumor necrosis factor family receptor. These cells were also intracellularly stained with the following antibodies: CTLA-4 (BD Biosciences, Sparks, MD), IL-17, and Foxp3 (eBioscience San Diego, CA). Before intracellular staining, cells were restimulated for $4 \mathrm{~h}$ with $25 \mathrm{ng} / \mathrm{ml}$ phorbol myristic acid and $250 \mathrm{ng} / \mathrm{ml}$ ionomycin in the presence of GolgiSTOP (BD Biosciences). Intracellular staining was conducted using an intracellular staining kit (eBioscience), according to the manufacturer's protocol. Flow cytometric analysis was performed on a FACSCalibur cytometer (BD Biosciences).

\section{Carboxylfluorescein succinimidyl ester (CFSE) labeling}

Mononuclear cells isolated from mouse spleens were washed once in $0.1 \%$ bovine serum albumin (BSA) in PBS and labeled with $1 \mu \mathrm{l} 5 \mathrm{mM}$ CFSE (Invitrogen, Carlsbad, CA) at a density of $1 \times 10^{7} \mathrm{cells} / \mathrm{ml}$ in $0.1 \%$ BSA in PBS for $10 \mathrm{~min}$ at $37^{\circ} \mathrm{C}$ in the dark. CFSE labeled cells were stimulated with anti-CD3 monoclonal antibody $(1 \mu \mathrm{g} / \mathrm{ml})$ and $\mathrm{Cll}(40 \mu \mathrm{g} / \mathrm{ml})$ for 3 days in 24 -well plates $(1 \times$ $10^{6} / \mathrm{ml}$ ). Flow cytometry was used to assess CFSE fluorescence.

\section{Real-time reverse transcription polymerase chain reaction (RT-PCR)}

Total RNA was extracted using the Trizol-LS reagent (Invitrogen). Total RNA $(2 \mu \mathrm{g})$ was reverse transcribed at $50^{\circ} \mathrm{C}$ for $2 \mathrm{~min}$, followed by $60^{\circ} \mathrm{C}$ for $30 \mathrm{~min}$. Quantitative PCR was performed using the FastStart DNA Master SYBR Green I kit and a LightCycler 480 Detection system (Roche, Meylan, France), as specified by the manufacturer. The crossing point $(\mathrm{Cp})$ was defined as the maximum of the second derivative from the fluorescence curve. Negative controls were included and contained all elements of the reaction mixture except for template DNA. For quantitation, we report relative mRNA expression levels of specific genes obtained using the $2^{-\Delta \mathrm{Ct}}$ method and used the $\beta$-actin housekeeping gene for normalization. The following gene-specific primers were used: tartrate-resistant acid phosphatase (TRAP) (forward: 5'-TCCTGGCTCAAAAAGC AGT-3'; reverse: 5'-ACATAGCCCACACCGTTCTC-3'), NFATc1 (forward: 5'-CGGGAAGAAGATGGTGCTGT-3'; reverse: 5'-TTGGACGGGGCTGGTTAT-3'), MMP9 (forward: 5'-CTG TCCAGACCAAGGGTACAGCCT-3'; reverse: 5'-GAGGTAT AGTGGGACACATAGTGG-3'), CTR (forward: 5'-CGGACT TTGACACAGCAGAA-3'; reverse: 5'-AGCAGCAATCGAC GAGT-3'), integrin- $\beta$ (forward: 5'-CTGTGGGCTTTAAGCA GC-3'; reverse: 5'-GAGGGTCGGTAATCCTCCTC-3'), cathepsin K (forward: 5'-CAGCAGAGGTGTGTACTATG-3'; reverse: 5'-GCGTTGTTCTTATTCCGAGC-3'), oscar (forward: 5'-CCTAGCCTCATACCCCCAG-3'; reverse: 5'-CAAACCG CCAGGCAGATTG-3'), RANKL (forward: 5'-TGTACTTTCG AGCGCAGATG-3'; reverse: 5'-CCACAATGTGTTGCAGTT CC-3'), osteocalcin (forward: 5'-CTGACCTCACAGATGCC AAGC-3'; reverse: 5'-TGGTCTGATAGCTCGTCACTTG-3'), runx2 (forward: 5'-TGTTCTCTGATCGCCTCAGTG-3'; reverse: 5'-AATGGGATCTGTAATCTGACTCT-3') and $\beta$-actin (forward: 5'-GAAATCGTGCGTGACATCAAAG-3'; reverse: 5'-TGTA GTTTCATGGATGCCACAG-3').

\section{Statistical analysis}

Data are presented as means \pm standard deviations (SDs). Statistical analyses were performed using the SPSS software (ver. 10.0 for Windows; SPSS, Chicago, IL). The intergroup analysis was performed using a Mann-Whitney $U$-test. $P$-values $<0.05$ were considered to indicate statistical significance.

\section{Acknowledgements}

This work was supported by a grant (A092258) from the Korea Healthcare Technology R\&D Project, Ministry for Health, Welfare, and Family Affairs, Republic of Korea.

\section{Disclosures}

The authors have no conflict of interest or any relevant financial interest in any company or institution that might benefit from this publication. 


\section{References}

Bettelli E, Oukka M, Kuchroo VK. T(H)-17 cells in the circle of immunity and autoimmunity. Nat Immunol 2007;8:345-50

Bluestone JA. Regulatory T-cell therapy: is it ready for the clinic? Nat Rev Immunol 2005;5:343-9

Camps M, Ruckle T, Ji H, Ardissone V, Rintelen F, Shaw J, Ferrandi C, Chabert C, Gillieron C, Francon B, Martin T, Gretener D, Perrin D, Leroy D, Vitte PA, Hirsch E, Wymann MP, Cirillo R, Schwarz MK, Rommel C. Blockade of $\mathrm{PI} 3$ Kgamma suppresses joint inflammation and damage in mouse models of rheumatoid arthritis. Nat Med 2005;11: 936-43

Chabaud M, Durand JM, Buchs N, Fossiez F, Page G, Frappart L, Miossec P. Human interleukin-17: A T cell-derived proinflammatory cytokine produced by the rheumatoid synovium. Arthritis Rheum 1999;42:963-70

Cho ML, Kang JW, Moon YM, Nam HJ, Jhun JY, Heo SB, Jin HT, Min SY, Ju JH, Park KS, Cho YG, Yoon CH, Park SH, Sung YC, Kim HY. STAT3 and NF-kappaB signal pathway is required for IL-23-mediated IL-17 production in spontaneous arthritis animal model IL-1 receptor antagonist-deficient mice. J Immunol 2006a;176:5652-61

Cho SG, Min SY, Park MJ, Lee KW, Cho YG, Cho ML, Chang HS, Park SH, Lee JW, Min WS, Kim CC, Kim HY. Immunoregulatory effects of allogeneic mixed chimerism induced by nonmyeloablative bone marrow transplantation on chronic inflammatory arthritis and autoimmunity in interleukin-1 receptor antagonist-deficient mice. Arthritis Rheum 2006b;54:1878-87

Chu CQ, Song Z, Mayton L, Wu B, Wooley PH. IFNgamma deficient C57BL/6 $(\mathrm{H}-2 \mathrm{~b})$ mice develop collagen induced arthritis with predominant usage of T cell receptor Vbeta6 and Vbeta8 in arthritic joints. Ann Rheum Dis 2003;62:983-90

Ferber IA, Brocke S, Taylor-Edwards C, Ridgway W, Dinisco C, Steinman L, Dalton D, Fathman CG. Mice with a disrupted IFN-gamma gene are susceptible to the induction of experimental autoimmune encephalomyelitis (EAE). J Immunol 1996;156:5-7

Fossiez F, Banchereau J, Murray R, Van Kooten C, Garrone P, Lebecque S. Interleukin-17. Int Rev Immunol 1998;16: 541-51

Groux H, O'Garra A, Bigler M, Rouleau M, Antonenko S, de Vries JE, Roncarolo MG. A CD4 ${ }^{+}$T-cell subset inhibits antigen-specific T-cell responses and prevents colitis. Nature 1997;389:737-42

Holmdahl R, Andersson M, Goldschmidt TJ, Gustafsson K Jansson L, Mo JA. Type II collagen autoimmunity in animals and provocations leading to arthritis. Immunol Rev 1990;118: 193-232

Hwang SY, Kim JY, Kim KW, Park MK, Moon Y, Kim WU, Kim HY. IL-17 induces production of IL-6 and IL-8 in rheumatoid arthritis synovial fibroblasts via NF-kappaB- and PI3-kinase/ Akt-dependent pathways. Arthritis Res Ther 2004;6:R120-8

Ikehara S, Good RA, Nakamura T, Sekita K, Inoue S, Oo MM, Muso E, Ogawa K, Hamashima Y. Rationale for bone marrow transplantation in the treatment of autoimmune diseases.
Proc Natl Acad Sci USA 1985;82:2483-7

Iwakura $\mathrm{Y}$, Ishigame $\mathrm{H}$, Saijo $\mathrm{S}$, Nakae S. Functional specialization of interleukin-17 family members. Immunity 2011;34:149-62

Kikly K, Liu L, Na S, Sedgwick JD. The IL-23/Th(17) axis: therapeutic targets for autoimmune inflammation. Curr Opin Immunol 2006;18:670-5

Kim WU, Lee WK, Ryoo JW, Kim SH, Kim J, Youn J, Min SY, Bae EY, Hwang SY, Park SH, Cho CS, Park JS, Kim HY. Suppression of collagen-induced arthritis by single administration of poly(lactic-co-glycolic acid) nanoparticles entrapping type II collagen: a novel treatment strategy for induction of oral tolerance. Arthritis Rheum 2002;46:1109-20

Kim KW, Cho ML, Park MK, Yoon CH, Park SH, Lee SH, Kim HY. Increased interleukin-17 production via a phosphoinositide 3-kinase/Akt and nuclear factor kappaB-dependent pathway in patients with rheumatoid arthritis. Arthritis Res Ther 2005; 7:R139-48

Kolls JK, Linden A. Interleukin-17 family members and inflammation. Immunity 2004;21:467-76

Komiyama $Y$, Nakae S, Matsuki T, Nambu A, Ishigame $H$, Kakuta S, Sudo K, Iwakura Y. IL-17 plays an important role in the development of experimental autoimmune encephalomyelitis. J Immunol 2006;177:566-73

Kotake S, Udagawa N, Takahashi N, Matsuzaki K, Itoh K, Ishiyama S, Saito S, Inoue K, Kamatani N, Gillespie MT, Martin TJ, Suda T. IL-17 in synovial fluids from patients with rheumatoid arthritis is a potent stimulator of osteoclastogenesis. J Clin Invest 1999;103:1345-52

Lee JH, Cho ML, Kim JI, Moon YM, Oh HJ, Kim GT, Ryu S, Baek SH, Lee SH, Kim HY, Kim SI. Interleukin 17 (IL-17) increases the expression of Toll-like receptor-2, 4 , and 9 by increasing IL-1beta and IL-6 production in autoimmune arthritis. J Rheumatol 2009;36:684-92

Lubberts E, Joosten LA, Oppers B, van den Bersselaar L, Coenen-de Roo CJ, Kolls JK, Schwarzenberger P, van de Loo FA, van den Berg WB. IL-1-independent role of IL-17 in synovial inflammation and joint destruction during collagen-induced arthritis. J Immunol 2001;167:1004-13

Lubberts E, Koenders MI, Oppers-Walgreen B, van den Bersselaar L, Coenen-de Roo CJ, Joosten LA, van den Berg WB. Treatment with a neutralizing anti-murine interleukin-17 antibody after the onset of collagen-induced arthritis reduces joint inflammation, cartilage destruction, and bone erosion. Arthritis Rheum 2004;50:650-9

Lubberts E. IL-17/Th17 targeting: on the road to prevent chronic destructive arthritis? Cytokine 2008;41:84-91

Lubberts E. Th17 cytokines and arthritis. Semin Immunopathol 2010;32:43-53

Murphy CA, Langrish $\mathrm{CL}$, Chen $\mathrm{Y}$, Blumenschein $\mathrm{W}$, McClanahan T, Kastelein RA, Sedgwick JD, Cua DJ. Divergent pro- and antiinflammatory roles for IL-23 and IL-12 in joint autoimmune inflammation. J Exp Med 2003;198: 1951-7

Myers LK, Rosloniec EF, Cremer MA, Kang AH. Collageninduced arthritis, an animal model of autoimmunity. Life Sci 


\section{7;61:1861-78}

Nakae S, Nambu A, Sudo K, Iwakura Y. Suppression of immune induction of collagen-induced arthritis in IL-17deficient mice. J Immunol 2003a;171:6173-7

Nakae S, Saijo S, Horai R, Sudo K, Mori S, Iwakura Y. IL-17 production from activated $T$ cells is required for the spontaneous development of destructive arthritis in mice deficient in IL-1 receptor antagonist. Proc Natl Acad Sci USA 2003b;100:5986-90

Pickens SR, Volin MV, Mandelin AM, 2nd, Kolls JK, Pope RM, Shahrara S. IL-17 contributes to angiogenesis in rheumatoid arthritis. J Immunol 2010;184:3233-41

Sato K, Suematsu A, Okamoto K, Yamaguchi A, Morishita Y, Kadono Y, Tanaka S, Kodama T, Akira S, Iwakura Y, Cua DJ, Takayanagi $\mathrm{H}$. Th17 functions as an osteoclastogenic helper $T$ cell subset that links $T$ cell activation and bone destruction. J Exp Med 2006;203:2673-82

Seki N, Sudo Y, Yoshioka T, Sugihara S, Fujitsu T, Sakuma S, Ogawa T, Hamaoka T, Senoh H, Fujiwara H. Type II collagen-induced murine arthritis. I. Induction and perpetuation of arthritis require synergy between humoral and cell-mediated immunity. J Immunol 1988;140:1477-84

Shahrara S, Huang Q, Mandelin AM, 2nd and Pope RM. $\mathrm{TH}-17$ cells in rheumatoid arthritis. Arthritis Res Ther 2008; 10:R93

Stuart JM, Cremer MA, Kang AH, Townes AS. Collageninduced arthritis in rats. Evaluation of early immunologic events. Arthritis Rheum 1979;22:1344-51

Tzartos JS, Friese MA, Craner MJ, Palace J, Newcombe J,
Esiri MM, Fugger L. Interleukin-17 production in central nervous system-infiltrating T cells and glial cells is associated with active disease in multiple sclerosis. Am J Pathol 2008; 172:146-55

van den Brink MR, Burakoff SJ. Cytolytic pathways in haematopoietic stem-cell transplantation. Nat Rev Immunol 2002;2:273-81

Wong CK, Ho CY, Li EK, Lam CW. Elevation of proinflammatory cytokine (IL-18, IL-17, IL-12) and Th2 cytokine (IL-4) concentrations in patients with systemic lupus erythematosus. Lupus 2000;9:589-93

Wooley PH, Luthra HS, Stuart JM, David CS. Type II collagen-induced arthritis in mice. I. Major histocompatibility complex (I region) linkage and antibody correlates. J Exp Med 1981;154:688-700

Ye P, Rodriguez FH, Kanaly S, Stocking KL, Schurr J, Schwarzenberger P, Oliver P, Huang W, Zhang P, Zhang J, Shellito JE, Bagby GJ, Nelson S, Charrier K, Peschon JJ, Kolls JK. Requirement of interleukin 17 receptor signaling for lung CXC chemokine and granulocyte colony-stimulating factor expression, neutrophil recruitment, and host defense. J Exp Med 2001;194:519-27

Zhang R, Qian J, Guo J, Yuan YF, Xue K. Suppression of experimental autoimmune uveoretinitis by Anti-IL-17 antibody. Curr Eye Res 2009;34:297-303

Zhou L, Lopes JE, Chong MM, Ivanov, II, Min R, Victora GD, Shen Y, Du J, Rubtsov YP, Rudensky AY, Ziegler SF, Littman DR. TGF-beta-induced Foxp3 inhibits $T(H) 17$ cell differentiation by antagonizing RORgammat function. Nature 2008;453:236-40 